University of Nebraska - Lincoln

DigitalCommons@University of Nebraska - Lincoln

January 1977

\title{
EXPECTED PHENOTYPIC RESPONSE IN WEANING WEIGHT OF BEEF CALVES FROM SELECTION FOR DIRECT AND MATERNAL GENETIC EFFECTS
}

\author{
L. Dale Van Vleck \\ University of Nebraska-Lincoln, dvan-vleck1@unl.edu \\ David St. Louis \\ Cornell University \\ J. I. Miller \\ Cornell University
}

Follow this and additional works at: https://digitalcommons.unl.edu/animalscifacpub

Part of the Animal Sciences Commons

Van Vleck, L. Dale; St. Louis, David; and Miller, J. I., "EXPECTED PHENOTYPIC RESPONSE IN WEANING WEIGHT OF BEEF CALVES FROM SELECTION FOR DIRECT AND MATERNAL GENETIC EFFECTS" (1977). Faculty Papers and Publications in Animal Science. 333.

https://digitalcommons.unl.edu/animalscifacpub/333

This Article is brought to you for free and open access by the Animal Science Department at DigitalCommons@University of Nebraska - Lincoln. It has been accepted for inclusion in Faculty Papers and Publications in Animal Science by an authorized administrator of DigitalCommons@University of Nebraska - Lincoln. 
Van Vleck, L. D., D. G. St. Louis, and J. I. Miller. 1977. Expected phenotypic response in weaning weight of beef calves from selection for direct and maternal genetic effect. Journal of Animal Science 44:360-367.

Abstract: An equation is derived to predict expected phenotypic response to selection when the trait under selection is influenced by both direct and maternal genetic effects. The expected phenotypic response after the $\mathrm{i}+1$ th generation of selection is $\mathrm{Pi}+1=(\mathrm{i}+1)\{$ Delta $\} \mathrm{D}+\mathrm{i}\{$ Delta $\} \mathrm{M}+$ \{Delta\} $\mathrm{MC}$ where $\{$ Delta\} $\mathrm{D}$ and $\{$ Delta\} $\mathrm{M}$ are the averages of the genetic selection differentials of the parents for the direct and maternal effects and $\{$ Delta\}MC is the maternal genetic selection differential for selected females. An example, corresponding to published reports of genetic variances and covariance for direct and maternal effects on weaning weight, illustrates the importance of the covariance term in long term response. With a large negative covariance, selection of males for direct and females for maternal genetic value would give greater expected response in progeny after the first generation than selection of females for direct genetic value.

Copyright $\odot 1977$ American Society of Animal Science. Used by permission. 


\title{
EXPECTED PHENOTYPIC RESPONSE IN WEANING WEIGHT OF BEEF CALVES FROM SELECTION FOR DIRECT AND MATERNAL GENETIC EFFECTS
}

\author{
L. D. Van Vleck, David St. Louis and J. I. Miller ${ }^{1}$ \\ Cornell University, Itbaca, NY 14853
}

\begin{abstract}
SUMMARY
An equation is derived to predict expected phenotypic response to selection when the trait under selection is influenced by both direct and maternal genetic effects. The expected phenotypic response after the $i+1^{\text {th }}$ generation of selection is $P_{i+1}=(i+1) \Delta D+i \Delta M+\Delta M_{C}$ where $\Delta \mathrm{D}$ and $\Delta M$ are the averages of the genetic selection differentials of the parents for the direct and maternal effects and $\Delta \mathrm{M}_{\mathrm{C}}$ is the maternal genetic selection differential for selected females. An example, corresponding to published reports of genetic variances and covariance for direct and maternal effects on weaning weight, illustrates the importance of the covariance term in long term response. With a large negative covariance, selection of males for direct and females for maternal genetic value would give greater expected response in progeny after the first generation than selection of females for direct genetic value.
\end{abstract}

(Key Words: Weaning Weight, Maternal Effects, Selection Response.)

\section{INTRODUCTION}

There is considerable evidence for an antagonism between direct genetic effects and maternal effects on weaning weight of beef cattle (Koch and Clark, 1955; Deese and Koger, 1967; Hohenboken and Brinks, 1970a,b; Koch et al., 1974; Mangus and Brinks, 1970). Whether the maternal effects are genetic or environmental has not, however, been resolved (Koch, 1972; Hohenboken, 1973). These reports have attempted to explain the relatively little long run progress made by individual selection for weaning weight. If, in fact, maternal genetic effects are important, selection could be modified to increase progress in the short run. The purpose

\footnotetext{
${ }^{1}$ Department of Animal Science.
}

of this paper is to describe how to evaluate expected genetic progress from selection for direct and maternal genetic effects.

\section{METHODS}

Methods are well known for calculating expected response from selection for a single trait or aggregate genotype and for calculating expected correlated responses in individual traits. In such cases, the assumption is made that the selection goal is the same for both males and females. If genetic maternal effects are important, however, there may be a short term advantage in selecting males for direct genetic value and females for maternal genetic value in order to optimize phenotypic response. Genetic response would, of course, be maximum with selection of both males and females for the aggregate genotype including direct and maternal genetic effects weighted by their net economic values (Henderson, 1963; VanVleck, 1970).

To simplify the derivation, two assumptions will be made: (1) all genetic effects are additive genetic effects and (2) the generation intervals for males and females are equal.

Let $I_{B}$ be the index used to select males with a standardized selection differential of $s_{B}$ and $I_{C}$ be the index used to select females with standardized selection differential $s_{C}$. The indexes may include records on relatives, including the individual being evaluated. Records on a different set of relatives may be used for males and females. The index may be predicting $\mathrm{H}=$ $v_{D} G_{D}+v_{M} G_{M}$ or $G_{D}$ or $G_{M}$ where $G_{D}$ is the additive direct genetic value, $G_{M}$ is the additive maternal genetic value, $v_{D}$ is the net economic value for an increase of one unit of the trait from direct genetic effects and $v_{M}$ is the net economic value of a one unit increase from maternal genetic effects. If selection is for such 360

an aggregate genotype, records of more than 
one kind of relative are required. The derivation of such indexes and calculation of expected responses are given by VanVleck (1970).

Let $\Delta D_{B}$ be the direct genetic superiority and $\Delta M_{B}$ be the maternal genetic superiority of males selected with the index, $I_{B}$. Similarly, let $\Delta D_{C}$ and $\Delta M_{C}$ be the corresponding genetic selection differentials for females selected with the index, $\mathbf{l}_{\mathbf{C}}$. As is commonly taught,

$$
\begin{aligned}
& \Delta \mathrm{D}_{\mathrm{B}}=\operatorname{Cov}\left(\mathrm{G}_{\mathrm{D} \alpha}, \mathrm{I}_{\mathrm{B} \alpha}\right) \mathrm{s}_{\mathrm{B}} / \sigma_{\mathrm{I}_{\mathrm{B}}} ; \\
& \Delta \mathrm{M}_{\mathrm{B}}=\operatorname{Cov}\left(\mathrm{G}_{\mathrm{M} \alpha}, \mathrm{I}_{\mathrm{B} \alpha}\right) \mathrm{s}_{\mathrm{B}} / \sigma_{\mathrm{I}_{\mathrm{B}}} ; \\
& \Delta \mathrm{D}_{\mathrm{C}}=\operatorname{Cov}\left(\mathrm{G}_{\mathrm{D} \alpha}, \mathrm{I}_{\mathrm{C} \alpha}\right) \mathrm{s}_{\mathrm{C}} / \sigma_{\mathrm{I}_{\mathrm{C}}} ; \\
& \Delta \mathrm{M}_{\mathrm{C}}=\operatorname{Cov}\left(\mathrm{G}_{\mathrm{M} \alpha}, \mathrm{I}_{\mathrm{C} \alpha}\right) \mathrm{s}_{\mathrm{C}} / \sigma_{\mathrm{I}_{\mathrm{C}}} .
\end{aligned}
$$

The covariances are between the index used for selection and either the direct genetic, $\mathrm{G}_{\mathrm{D} \alpha}$, or maternal genetic, $G_{M \alpha}$, value of $\alpha$, the animal being evaluated. The standard deviations, $\sigma_{I_{B}}$ and $\sigma_{I_{C}}$, are of the indexes used for male and female selection.

The expected genetic values of progeny for direct and maternal effects from mating selected males and females will as usual be $\Delta D=$ $\left(\Delta D_{B}+\Delta D_{C}\right) / 2$ and $\Delta M=\left(\Delta M_{B}+\Delta M_{C}\right) / 2$. The expected phenotypic response in the first generation, however, will be

$$
\mathbf{P}_{1}=\frac{\Delta \mathrm{D}_{\mathrm{B}}+\Delta \mathrm{D}_{\mathrm{C}}}{2}+\Delta \mathrm{M}_{\mathrm{C}}=\Delta \mathrm{D}+\Delta \mathrm{M}_{\mathrm{C}}
$$

The direct genetic effects of the progeny as contributed by their parents will be expressed, but the maternal genetic effects of the progeny cannot be expressed although the maternal genetic effects of the selected female parents will be expressed. With the assumption of equal male and female generation intervals, the expected phenotypic response in the next generation can be calculated (with the added usual assumption that selection has not significantly altered the genetic variances and covariance of the direct and maternal effects). The mean direct and maternal genetic values for generation 1 are $\Delta D$ and $\Delta M$. The expected direct genetic superiorities for males and females selected to produce generation 2 are: $\Delta D+$ $\Delta D_{B}$ and $\Delta \mathrm{D}+\Delta D_{C}$. The mean genetic maternal value of generation 1 females, $\Delta M$, will be expressed in generation 2 progeny as will the added maternal superiority of those selected to be dams, $\Delta M_{C}$.

Thus, $\mathrm{P}_{2}=\left[\left(\Delta \mathrm{D}+\Delta \mathrm{D}_{\mathrm{B}}+\Delta \mathrm{D}+\Delta \mathrm{D}_{\mathrm{C}}\right) / 2\right]$ $+\Delta \mathrm{M}+\Delta \mathrm{M}_{\mathrm{C}}$. By adding and subtracting $\Delta M_{B} / 2, P_{2}=2 \Delta D+2 \Delta M+\left[\left(\Delta M_{C}-\Delta M_{B}\right) / 2\right]$. In more general terms, $P_{i+1}=(i+1)(\Delta D+\Delta M)+$
$\left[\left(\Delta M_{C}-\Delta M_{B}\right) / 2\right]$ or $P_{i+1}=(i+1) \Delta D+i \Delta M+$ $\Delta \mathrm{M}_{\mathrm{C}}$.

These equations can be used to compare expected phenotypic response from selection using $I_{B}$ and $I_{C}$ for a specified number of generations. The preceding equation also demonstrates that gain in maternal genetic ability lags one generation behind gain in direct genetic ability. The temporary gain in maternal ability from cow selection appears as a constant in each generation. Of particular interest for beef breeders who plan to remain in business for only a short time may be selection of males for direct genetic value and females for maternal genetic value. The genetic variances and covariance of and between the direct and maternal components will determine the practicality of such selection.

\section{EXAMPLES}

Two sets of standardized genetic variances and covariances will be used-Set $1: \sigma_{\mathrm{G}}^{2}=.30$, $\sigma_{\mathrm{G}_{M}}^{2}=.40$ and $\sigma_{\mathrm{G}_{\mathrm{D}} \mathrm{G}_{\mathrm{M}}}=-.30$ corresponding to a genetic correlation of -.87 ; and Set 2: $\sigma_{\mathrm{G}_{\mathrm{D}}}^{2}=.30, \sigma_{\mathrm{G}_{\mathrm{M}}}^{2}=.40$ and $\sigma_{\mathrm{G}_{\mathrm{D}} \mathrm{G}_{\mathrm{M}}=-.02}$ corresponding to a genetic correlation of -.06 . An additional environmental covariance between offspring and dam records of -.35 was assumed in the second set. Such an environmental covariance may explain the low correlation between offspring and dam weaning weights which may be caused by a correlation between the maternal environment of the dam and her maternal ability (Koch, 1972; Willham, 1972).

The summary of calculations for use of four sets of records typically available for selection with beef cattle are summarized in tables 1 and 2 . The economic values were equal for the case of selection for both components. The methods of calculation have been described by VanVleck (1970).

The standardized expected genetic superiorities in table 1 or table 2 can be used to calculate expected phenotypic gain at specified generations for specified selection intensities of males and females with a particular phenotypic standard deviation for weaning weight. For example, assume $\mathrm{s}_{\mathrm{B}}=1.25, \mathrm{~s}_{\mathrm{C}}=.6$ and a phenotypic standard deviation of 27.3 kilograms. The calculated values of $\Delta D, \Delta M$ and $\Delta M_{C}$ are shown in tables 3 and 4 . The calculations for the first value in table 3 are:

$$
\Delta \mathrm{D}_{\mathrm{B}}=(.15)(1.25)(27.3)=5.12 ;
$$


TABLE 1. SELECTION INDEX WEIGHTS AND STANDARDIZED EXPECTED GENETIC SUPERIORITY FOR SELECTION ON FOUR DIFFERENT SETS OF RECORDS WHEN STANDARDIZED VARIANCES ARE: DIRECT GENETIC, ,30, AND MATERNAL GENETIC, .40, WITH GENETIC COVARIANCE OF - .30

\begin{tabular}{|c|c|c|c|c|}
\hline \multirow[b]{2}{*}{ Records used } & \multirow{2}{*}{$\begin{array}{l}\text { Selection } \\
\text { for direct } \\
\text { or maternal } \\
\text { trait }\end{array}$} & \multirow[b]{2}{*}{$\begin{array}{l}\text { Index } \\
\text { weights }\end{array}$} & \multicolumn{2}{|c|}{$\begin{array}{l}\text { Standardized expected } \\
\text { genetic superiority }\end{array}$} \\
\hline & & & $\begin{array}{l}\overline{\Delta D_{B}} \\
\text { or } \mathrm{C}\end{array}$ & $\begin{array}{l}\Delta M_{B} \\
\text { or } C\end{array}$ \\
\hline Own & $\mathrm{D}$ & .15 & .15 & -.10 \\
\hline 35 phs progeny b & D & 1.48 & .47 & -.47 \\
\hline Own, dame & $\mathrm{D}$ & $.15, .08$ & .17 & -.11 \\
\hline Own, 35 phs & $\mathrm{D}$ & $.10, .66$ & .25 & -.24 \\
\hline Own & $\mathbf{M}$ & -.10 & -.15 & .10 \\
\hline 35 phs progenyb & $M$ & -1.48 & -.47 & .47 \\
\hline Own, damc & $M$ & $-.10,-.05$ & -.17 & .11 \\
\hline Own, 35 phs & $\mathbf{M}$ & $-.05,-.70$ & -.27 & .24 \\
\hline Own & $\mathrm{D}+\mathrm{M}$ & .05 & .15 & -.10 \\
\hline 35 phs progenyb & $\mathrm{D}+\mathrm{M}$ & .00 & .00 & .00 \\
\hline Own, damc & $\mathrm{D}+\mathrm{M}$ & $.05, .03$ & .17 & -.11 \\
\hline Own, 35 phs & $D+M$ & $.05,-.04$ & .10 & -.04 \\
\hline
\end{tabular}

\footnotetext{
${ }^{\mathrm{a}}$ These values would be multiplied by the phenotypic standard deviation and the standardized selection intensity factor.

${ }^{\mathrm{b}}$ Selection in this case is for males only.

${ }^{\mathrm{c}}$ Selection for females only.
}

TABLE 2. SELECTION INDEX WEIGHTS AND STANDARDIZED EXPECTED GENETIC SUPERIORITY FOR SELECTION ON FOUR DIFFERENT SETS OF RECORDS WHEN STANDARDIZED VARIANCES ARE: DIRECT GENETIC, .30, AND MATERNAL GENETIC, .40, WITH STANDARDIZED GENETIC COVARIANCE OF -.02 AND ENVIRONMENTAL COVARIANCE BETWEEN DAUGHTER AND DAM OF - .35

\begin{tabular}{|c|c|c|c|c|}
\hline \multirow[b]{2}{*}{ Records used } & \multirow{2}{*}{$\begin{array}{l}\text { Selection } \\
\text { for direct } \\
\text { or maternal } \\
\text { trait }\end{array}$} & \multirow[b]{2}{*}{$\begin{array}{l}\text { Index } \\
\text { weights }\end{array}$} & \multicolumn{2}{|c|}{$\begin{array}{l}\text { Standardized expected } \\
\text { genetic superiority }\end{array}$} \\
\hline & & & $\begin{array}{l}\Delta \mathrm{D}_{\mathrm{B}} \\
\text { or } \mathrm{C}\end{array}$ & $\begin{array}{l}\Delta \mathrm{M}_{\mathrm{B}} \\
\text { or } \mathrm{C}\end{array}$ \\
\hline Own & $\mathrm{D}$ & .29 & .29 & .18 \\
\hline 35 phs progenyb & D & 1.48 & .47 & -.03 \\
\hline Own, damc & D & $.29, .15$ & .33 & .20 \\
\hline Own, 35 phs & D & $.25, .56$ & .34 & .12 \\
\hline Own & $\mathbf{M}$ & .18 & .29 & .18 \\
\hline 35 phs progeny $b$ & $\mathbf{M}$ & -.10 & -.47 & .03 \\
\hline Own, damc & $M$ & $.18, .09$ & .33 & .20 \\
\hline Own, 35 phs & $M$ & $.19,-.19$ & .22 & .19 \\
\hline Own & $\mathrm{D}+\mathrm{M}$ & .47 & .29 & .18 \\
\hline 35 phs progenyb & $\mathbf{D}+\mathbf{M}$ & 1.38 & .47 & -.03 \\
\hline Own, dame & $\mathrm{D}+\mathrm{M}$ & $.48, .25$ & .33 & .20 \\
\hline Own, 35 phs & $D+M$ & $.44, .36$ & .32 & .16 \\
\hline
\end{tabular}

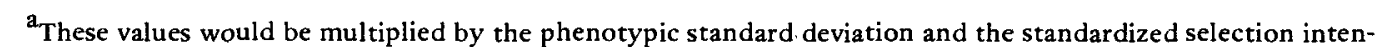
sity factor.

${ }^{b}$ Selection in this case is for males only.

$\mathrm{c}_{\text {Selection for females only. }}$ 


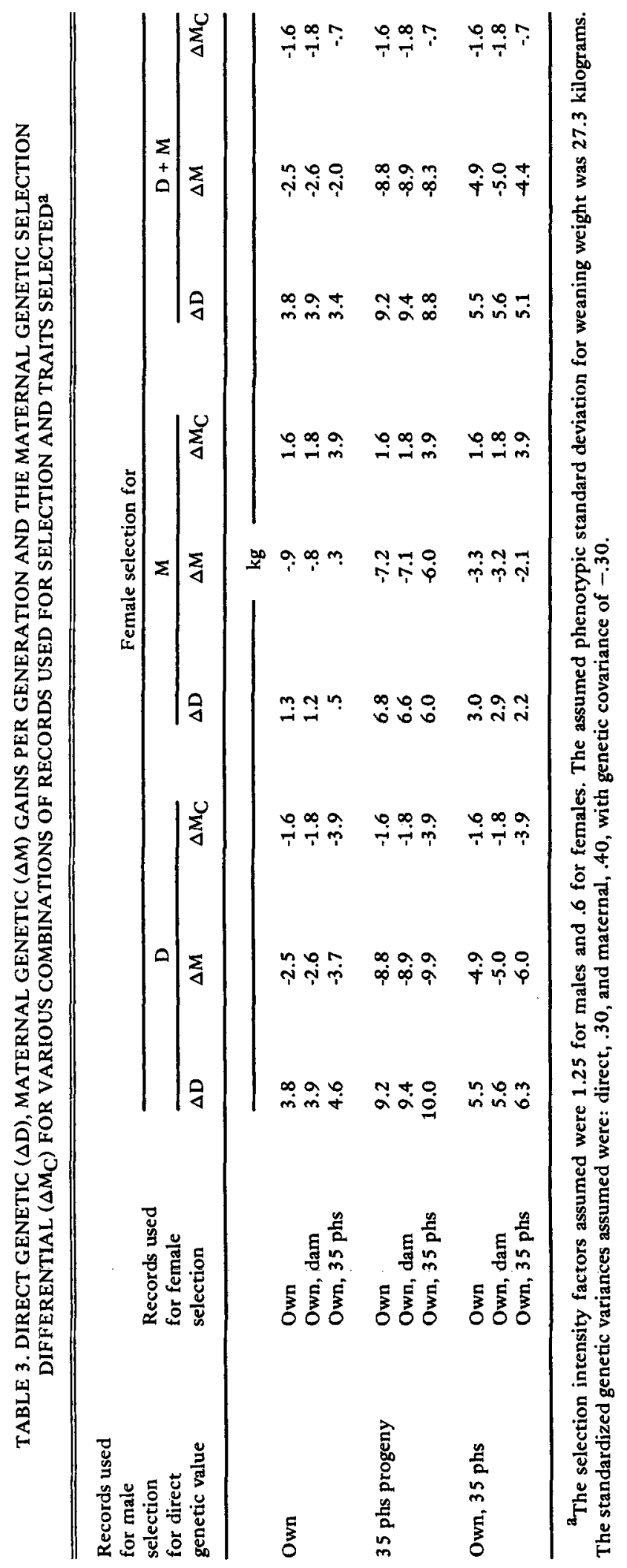




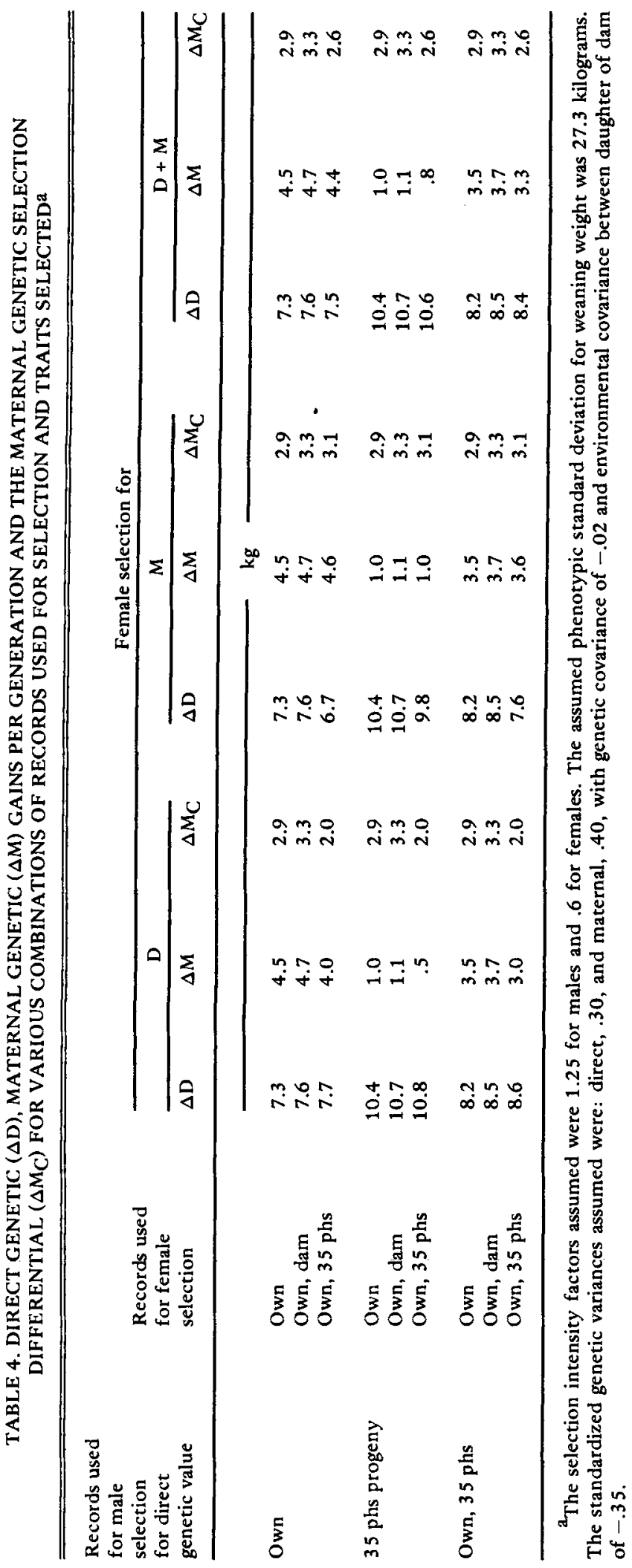




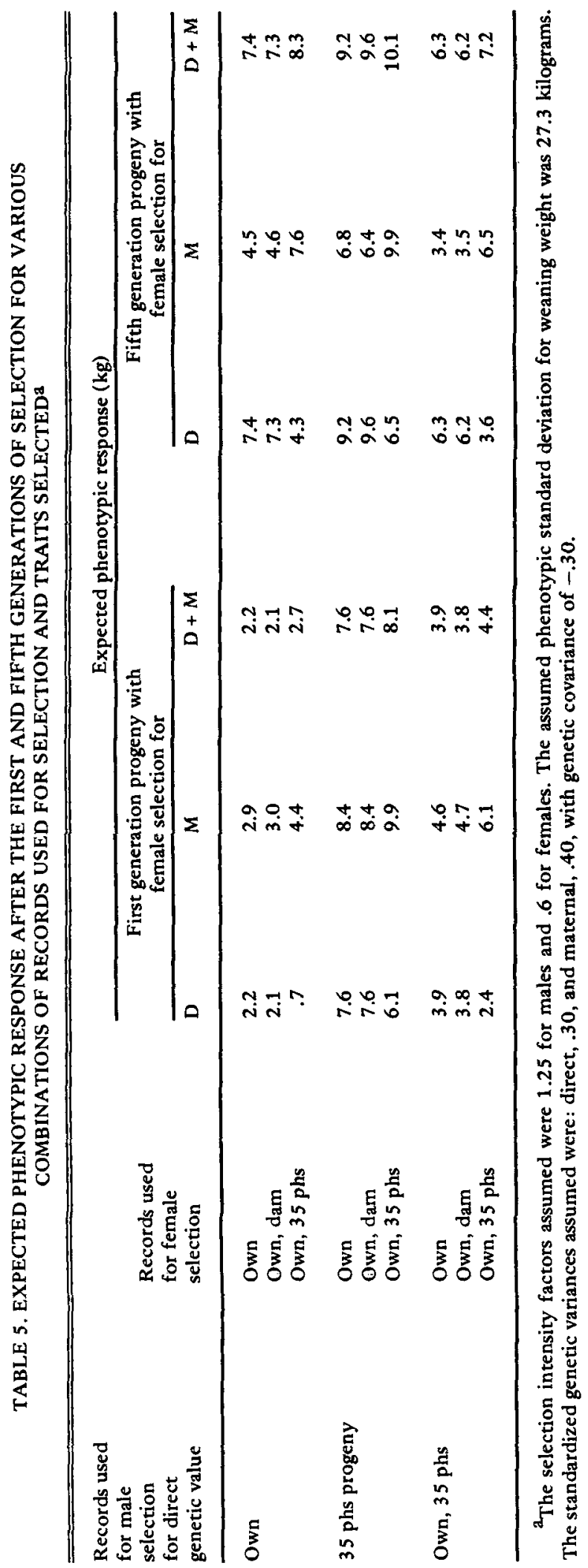




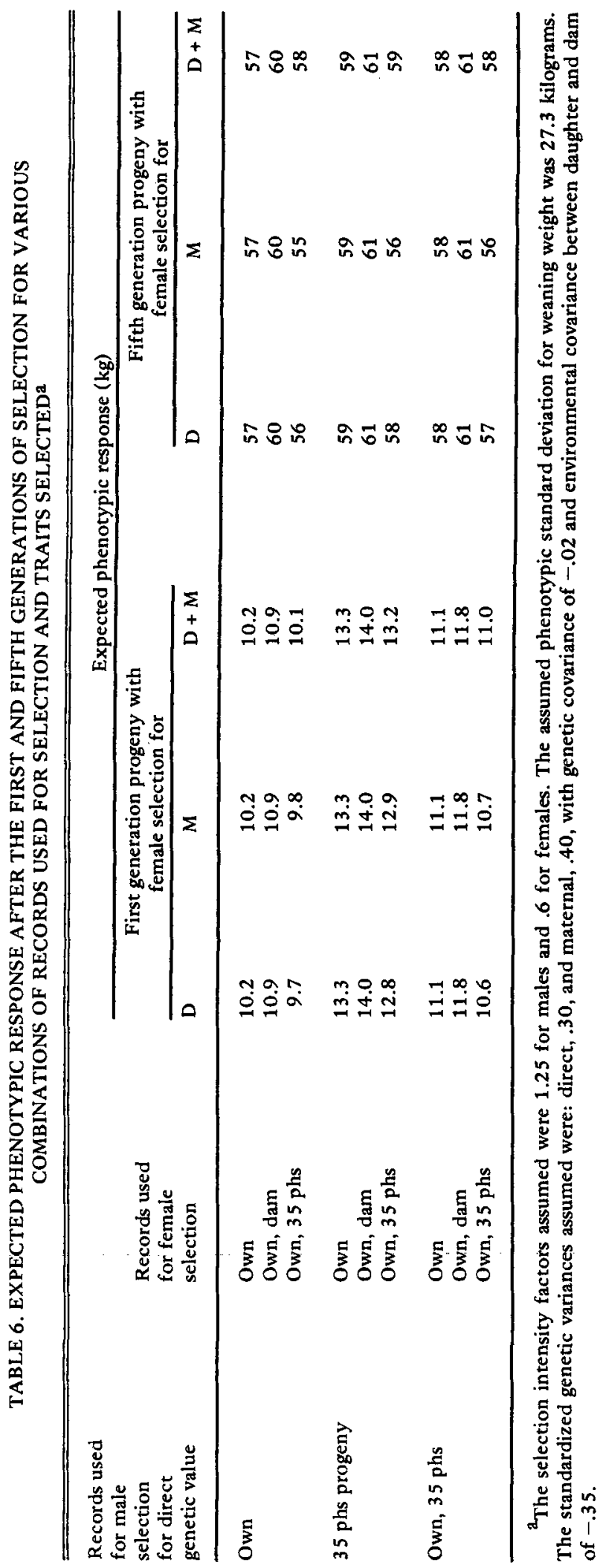




$$
\begin{aligned}
& \Delta \mathrm{M}_{\mathrm{B}}=(-.10)(1.25)(27.3)=-3.41 ; \\
& \Delta \mathrm{D}_{\mathrm{C}}=(.15)(.6)(27.3)=2.46 ; \\
& \Delta \mathrm{M}_{\mathrm{C}}=(-.10)(.6)(27.3)=-1.64
\end{aligned}
$$

so that $\Delta \mathrm{D}=(5.12+2.46) / 2=3.79$ and $\Delta M=$ $(-3.41-1.64) / 2=-2.52$ when selection is for direct genetic value of males and females. If selection among females is for maternal genetic value, then $\Delta \mathrm{D}_{\mathrm{C}}=(-.15)(.6)(27.3)=-2.46$ and $\Delta \mathrm{M}_{\mathrm{C}}=(.10)(.6)(27.3)=1.64$ so that $\Delta \mathrm{D}=$ $5.12-2.46) / 2=1.33$ and $\Delta M=(-3.41+$ 1.64) $/ 2=-.88$.

The values in table 3 illustrate why, with a large negative covariance between direct and maternal genetic effects, total progress is so slow. As the direct component increases in one generation, a generation later most of that gain is offset by a decrease in the maternal component. If the covariance is near zero, then relatively rapid gain can be made in both components. The next step in the calculation, however, is to use the values in tables 3 and 4 to predict the phenotypic response for any specified number of generations.

Expected progeny responses for the first generation of selection and after five generations are shown in tables 5 and 6. Table 5 illustrates again what was apparent in tables 1 and 3, that genetic improvement is difficult with the large negative covariance. For example, the combinations of progeny testing males with any of the three systems for females have a large expected response in the first generation but little after that due to the genetic antagonism.

Another illustration is that first generation response due to using the dam's records in addition to the female's own is the same as if the dam's record was not used. The breakdown of the total response shows that the additional gain in direct genetic value is counterbalanced by a decrease in the maternal component as can be seen in table 3. Similarly, using the sire's proof when selecting for direct value with the female's own record leads to more direct genetic gain than only using the female's own record but the total response is decreased because of the larger negative value of $\Delta \mathrm{M}_{\mathrm{C}}$.

All combinations shown in table 5 have a greater expected response in the first generation if selection of females is for maternal genetic value rather than direct genetic value. The combinations including female selection based on own record and sire's proof even show an advantage for maternal selection of females when expected responses after five generations are compared.

If the genetic covariance is small as in the example for tables 2, 4 and 6 , the expected responses after the first and fifth generation of selection are remarkably similar for all combinations of male and female selection and whether or not female selection is for direct or maternal genetic value.

In these examples, the maternal genetic variance was larger than the direct genetic variance. If the opposite is thought to be true, expected responses with other combinations of genetic variances and covariance as well as for other combinations of relatives can be easily calculated according to the same procedure. Selection with highest expected response can then be practiced or balanced against the cost of the selection plan.

\section{LITERATURE CITED}

Deese, R. E. and M. Koger. 1967. Maternal effects of preweaning growth rate in cattle. J. Anim. Sci. $26: 250$.

Henderson, C. R. 1963. Selection index and expected genetic advance. In: Statistical Genetics and Plant Breeding. NAS-NRC 982-141.

Hohenboken, W. D. 1973. Relationships between direct and maternal effects on weaning weight in cattle. In Ralph Bogart (Ed.) Genetics Lectures. Vol. 3. Oregon State University Press, Corvallis.

Hohenboken, W. D. and J. S. Brinks. 1970a. Relationships between direct and maternal effects on growth in Herefords. II. Partitioning of covariance between relatives. J. Anim. Sci. 32:26.

Hohenboken, W. D. and J. S. Brinks. 1970b. Relationships between direct and maternal effects on growth in Herefords. III. Covariance of paternal half-brother and sister performance. J. Anim. Sci. 32:35.

Koch, Robert M. 1972. The role of maternal effects in animal breeding: VI. Maternal effects in beef cattle. J. Anim. Sci. 35:1316.

Koch, Robert M. and R. T. Clark. 1955. Genetic and environmental relationships among economic traits in beef cattle. III. Evaluating maternal environment. J. Anim. Sci. 14:979.

Koch, Robert M., K. E. Gregory and L. V. Cundiff. 1974. Selection in beef cattle. II. Selection response. J. Anim. Sci. 39:459.

Mangus, W. L. and J. S. Brinks. 1970. Relationships between direct and maternal effects on growth in Herefords. I. Environmental factors during preweaning growth. J. Anim. Sci. 32:17.

VanVleck, L. D. 1970. Index selection for direct and maternal genetic components of economic traits. Biometrics 26:477.

Willham, R. L. 1972. The role of maternal effects in animal breeding: III. Biometrical aspects of maternal effects in animals. J. Anim. Sci. 35:1288. 